\title{
Morfología de la cementita en aceros arqueológicos que han sufrido incendio(*)
}

\author{
A.J. Criado-Martín*, L. García*, M. Cartón*, A.J. Criado-Portal*, C. Dietz** y J.A. Martínez*
}

\begin{abstract}
Resumen Se presenta un estudio metalográfico de piezas arqueológicas de acero, encontradas en distintos yacimientos arqueológicos, cuyas microestructuras características revelan que se han visto afectadas por niveles de incendio. El estudio se ha realizado mediante FEG (Field Emission Gun). Se han reproducido en el laboratorio las estructuras de los aceros arqueológicos.
\end{abstract}

Palabras clave Aceros arqueológicos; Estructuras metalográficas; Carburos de hierro; MEB; Arqueometalurgia.

\section{Morphology of the cementite in archaeological steels that have suffered fire}

\begin{abstract}
We present a metallographic study of archaeological artefacts of steel, had been found in different archaeological sites, which characteristic microstructures reveal that have been affected by levels of fire. Study was performed using FEG (Field Emission Gun). In the laboratory, they are reproduced structures of steels archaeological.
\end{abstract}

Keywords Archaeological steels; Metallographic structures; Iron carbides; SEM; Archaeometallurgy.

\section{INTRODUCCIÓN}

Son muchos los yacimientos arqueológicos que presentan niveles de incendio. El incendio fortuito o provocado a lo largo de la historia de la humanidad, es un hecho muy extendido. Sitio y asalto de ciudades y villas, asaltos a fortificaciones, arrasamiento de territorios e incendios no provocados, han dejado su huella en numerosos yacimientos arqueológicos. Muchos de estos niveles de incendio han sido fáciles de detectar por las huellas que dejan en los materiales y en las construcciones. Los aceros al carbono pueden ser testigos muy valiosos para certificar el ciclo térmico de un incendio. Si este incendio no alcanza las temperaturas y tiempos de transformaciones de fase necesarios, en el diagrama hierro-carbono, no quedará ningún testimonio en la estructura final de la pieza de acero que lo haya sufrido. Sin embargo, en aquellos casos en que la temperatura alcanzada se acerque o supere la isoterma de transformación eutectoide $\left(\approx 720^{\circ} \mathrm{C}\right)$ y el tiempo permanecido a estas temperaturas sea el necesario, el incendio dejará una huella en la microestructura del acero de la pieza arqueológica. Si se supera la temperatura eutectoide, aun para tiempos muy cortos (segundos o minutos), la transformación será más o menos efectiva, pero mostrará cambios microestructurales fácilmente detectables. Para el caso de llegar a temperaturas próximas al eutectoide $\left(600^{\circ} \mathrm{C}\right.$ a $\left.700{ }^{\circ} \mathrm{C}\right)$, los tiempos necesarios, para dejar huellas observables en la microestructura final deberán ser más prolongados; se necesitarán algunas horas de permanencia a esa temperatura para que los efectos sean visibles.

En todos los casos la estructura producida es una globulización de la cementita de la perlita, más o menos completa. Esta globulización se efectúa por mecanismos bien distintos según que se produzca durante un enfriamiento lento desde temperaturas superiores a la eutectoide, o bien, por calentamiento prolongado a temperaturas inferiores a ésta.

(•) Trabajo recibido el día 13 de septiembre de 2012 y aceptado en su forma final el día 21 de febrero de 2013.

* Dpto. de Ciencia de los Materiales e Ingeniería Metalúrgica, Universidad Complutense de Madrid, Ciudad Universitaria 28040-Madrid, E-mail: gslaura@quim.ucm.es.

** Centro de Arqueometría y Análisis Arqueológico (C.A.I. AAA), Facultad de Geografía e Historia, Universidad Complutense de Madrid, Edificio B, C/ Profesor Aranguren, s/n, Ciudad Universitaria 28040-Madrid. 
En el primer caso, si la velocidad de enfriamiento no supera, o es muy inferior, a $1{ }^{\circ} \mathrm{C} / \mathrm{min}$, la globulización de la cementita se produce de una manera muy eficaz, siendo más completa cuanto mayor sea el \% C en masa en el acero. Para contenidos en carbono próximos al eutectoide, eutectoides e hipereutectoides, la perlita se globuliza eficazmente incluso para velocidades de enfriamiento superiores a la señalada (Fig. 1) ${ }^{[1-4]}$.

En el segundo caso, cuando la globulización se produce por un calentamiento prolongado a temperaturas inferiores, pero próximas al eutectoide, el mecanismo es distinto, se hace más lento y muy dependiente de la difusión ${ }^{[5}$ y 6$]$. Esta globulización se produce en dos etapas bien diferenciadas; una primera etapa de escalonamiento y otra etapa, posterior, de globulización y crecimiento.

En la primera etapa, las láminas prismáticas de la cementita se segmentan o escalonan por aquellos puntos singulares de su superficie, (como defectos de crecimiento, emergencia de dislocaciones, etc.), donde la energía libre es mayor y puede facilitar la disolución de esa zona del cristal en la ferrita, favorecida, también, por el aumento de la solubilidad del carbono en la ferrita (de 0,008 \% C en masa a temperatura ambiente pasa a $0,032 \% \mathrm{C}$ en masa a temperatura $\approx 720^{\circ} \mathrm{C}$ ).

Transcurrida esta etapa se produce la segunda, de esferoidización y crecimiento de los cristales segmentados de cementita. En esa etapa se produce una competencia en el crecimiento de unos cristales frente a otros, creciendo los de mayor tamaño a costa de los más pequeños (Fig. 2) 2 $^{[2,5 \text { y } 6]}$.

Las diferencias de energías libres en las interfases de las partículas favorecen el crecimiento de unos frente a otros. La cinética de crecimiento está controlada por la ecuación (1):

$$
(r)^{3}-r_{0}^{3}=k t
$$

donde $\mathrm{r}_{\mathrm{o}}$ es el radio medio del cristal para $\mathrm{t}=0$, siendo, por tanto, el crecimiento de los carburos una relación lineal con respecto al tiempo. Para la ecuación anterior $\mathrm{k}$ es (2):

$$
\mathrm{k} \approx \mathrm{D} \cdot \gamma \cdot \mathrm{Xe}
$$

donde $\mathrm{D}$ es el coeficiente de difusión del carbono en ferrita; $\gamma$ es la energía interfacial; Xe es la solubilidad en el equilibrio para cristales muy grandes de carburo de hierro.

Sustituyendo el valor de k (2) en la ecuación (1), queda la ecuación (3):

$$
(r)^{3}-r_{o}^{3}=D \cdot Y \cdot X e \cdot t
$$

Como se deduce de estas ecuaciones los tiempos prolongados favorecen el crecimiento de las partículas cristalinas de cementita. La consecuencia es que la globulización de la cementita, a temperaturas por

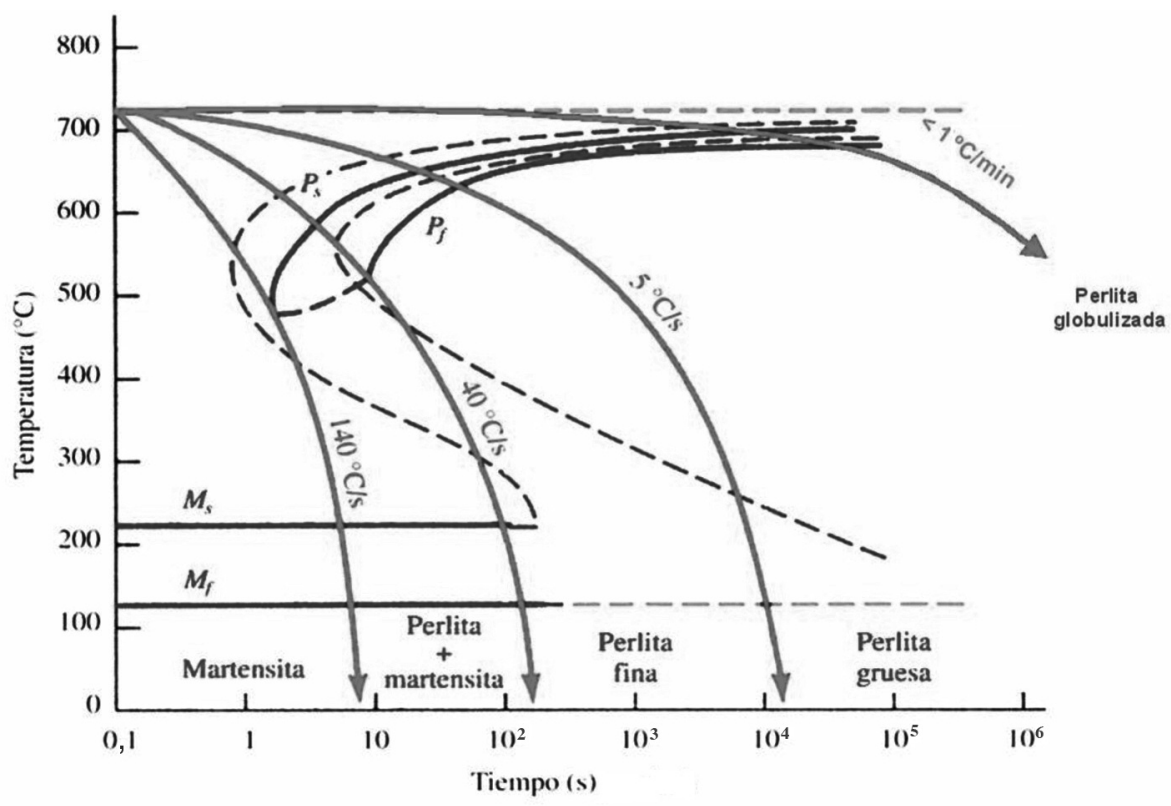

Figura 1. Diagrama de enfriamiento continuo.

Figure 1. Continuous cooling curves. 
FASE DE ENGROSAMIENTO

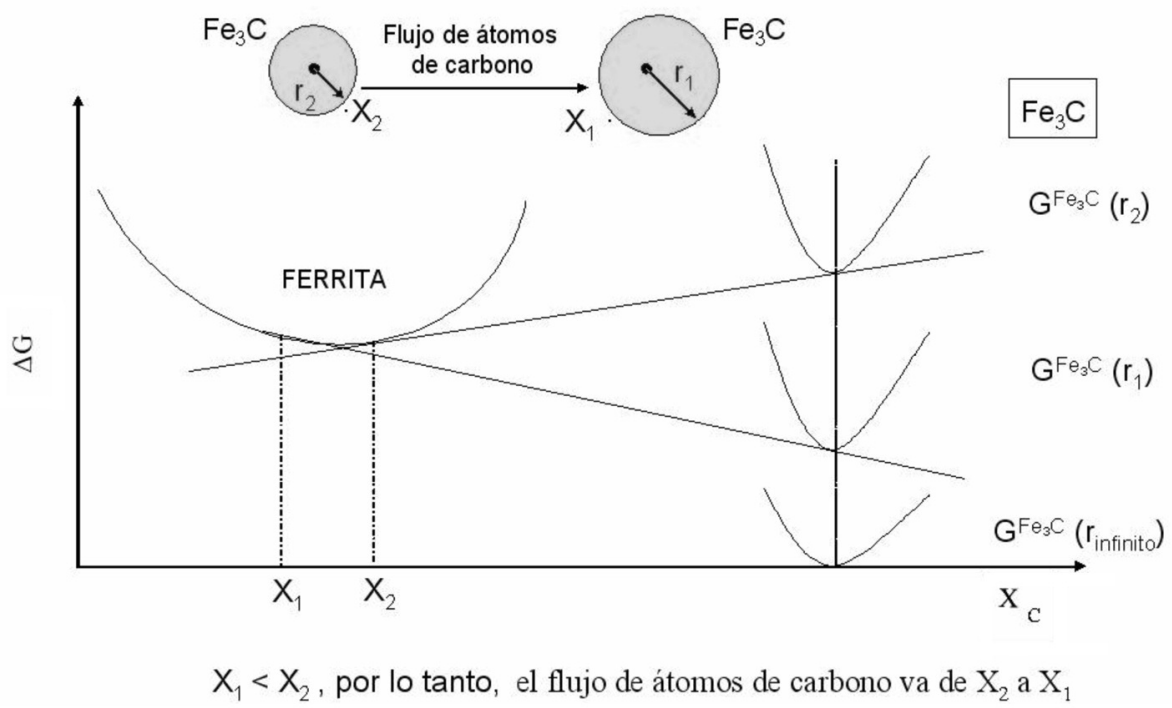

Figura 2. Diagrama de etapa de engrosamiento.

Figure 2. Thickening phase diagram.

debajo y cercanas al eutectoide, necesitan tiempos largos para completar el proceso.

En ambos casos, la globulización de la cementita durante el enfriamiento lento, desde temperaturas superiores al eutectoide, y la globulización a temperaturas cercanas pero inferiores al eutectoide, favorecen las morfologías globulares o esferoidizadas, por ser las que presentan menor energía superficial, es decir, menor área superficial para un volumen dado

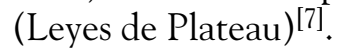

En esta investigación se han estudiado piezas arqueológicas de acero que sufrieron un incendio. Las microestructuras encontradas presentan perlita globulizada pero con morfologías cristalinas idiomórficas para la cementita. El crecimiento característico de un compuesto intermetálico, como la cementita, es de tipo planar ${ }^{[1]}$, lo que, inevitablemente, nos lleva a morfologías poliédricas de alta esferoidicidad.

El estudio metalográfico se ha llevado a cabo mediante un microscopio electrónico de barrido de cátodo termoiónico con filamento de wolframio (FEG). El modelo empleado es el Jeol 6400 JSM que proporciona imágenes y datos físico-químicos de la superficie de la muestra. Consta de tres detectores: detector de electrones secundarios, cuya resolución de imagen es a $35 \mathrm{KV}$, detector para trabajar a $8 \mathrm{~mm}$ de distancia con una resolución de imagen de 3,5 nm y detector para trabajar a $39 \mathrm{~mm}$ de distancia con una resolución de imagen de $10 \mathrm{~nm}$. Proporciona imágenes en electrones retrodispersados con una resolución de imagen de $10 \mathrm{~nm}$, a $8 \mathrm{~mm}$ de distancia de trabajo. Además, puede realizar análisis elemental cualitativo (EDS) con una resolución de $133 \mathrm{eV}$.

\section{TÉCNICA EXPERIMENTAL}

Aunque son muchos los yacimientos arqueológicos que presentan niveles de incendio, nuestro estudio lo hemos realizado de forma exhaustiva en los siguientes yacimientos:

- Villa romana del Saucedo en Talavera la Nueva (Toledo) (s. IV). Arqueólogo director D. M. Bendala Galán y Dª . R. Castelo.

- Ciudad de Numancia, (Soria) (s. I a.C. y I d.C.). Arqueólogo director D. A. Jimeno.

- Solar de casas al lado de la iglesia de San Vicente (Vitoria), (s. XIII). Arqueólogo director D. R. Arbosa.

En este trabajo vamos a discutir las microestructuras observadas en tres piezas arqueológicas de acero de los yacimientos antes citados:

- Clavo (Villa del Saucedo) (Fig. 3)

- Punta de lanza (Numancia) (Fig. 4)

- Anilla de cota de malla (Vitoria) (Fig. 5)

En todos los casos estudiados, se trata de estructuras de enfriamiento muy lento después de haber alcanzado picos de temperaturas que superaron la transformación eutectoide por cortos periodos de tiempo. Se ha imitado en el laboratorio un trata- 


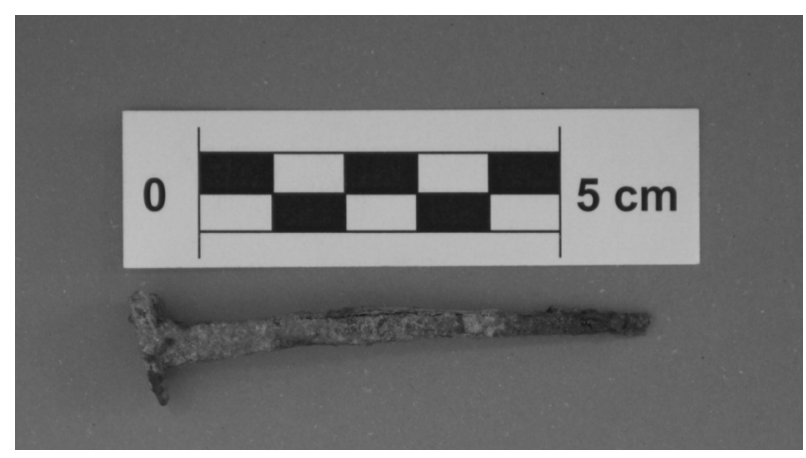

Figura 3. Imagen del clavo hallado en la Villa romana del Saucedo en Talavera la Nueva $(\text { Toledo })^{[8]}$.

Figure 3. Nail image found in the Villa Romana del Saucedo in Talavera la Nueva (Toledo ${ }^{[8]}$.

miento térmico, simulando lo que ocurrió en los incendios detectados con las piezas arqueológicas. Se realizó el calentamiento en un horno eléctrico tipo Carbolite modelo ELF11/14B hasta los $(750-780)^{\circ} \mathrm{C}$. Se mantuvo el calentamiento entre 10 y $30 \mathrm{~min}$ y, después, se dejó enfriar en el horno con un gradiente térmico inferior a $0,5^{\circ} \mathrm{C} / \mathrm{min}$.

Las muestras extraídas de las piezas fueron embutidas en resina Rèsine Mecaprex KM-U. Se desbas- taron mediante discos abrasivos en agua de Buheler de grano $240,320,600$ y 2.000 , y posterior pulido en alúmina $\alpha(0,3 \mu \mathrm{m})$ y alúmina $\gamma(0,03 \mu \mathrm{m})$, en paño de pulir Buheler. El ataque químico realizado se llevó a cabo con Nital al 2 \%, en baño de ultrasonidos, durante 1 min y $30 \mathrm{~s}$. Para eliminar restos del ataque, a los que es muy sensible el microscopio electrónico utilizado (FEG), se realizó una limpieza con agua destilada, en baño de ultrasonidos, con unas gotas de tensioactivo. Finalmente, para la observación de las muestras, se metalizan con oro durante $30 \mathrm{~s}$, con una intensidad de corriente de $20 \mathrm{~mA}$, y espesor de $3 \mathrm{~nm}$ de oro, para no interferir en las imágenes obtenidas de los cristales de carburo de hierro.

\section{RESULTADOS Y DISCUSIÓN}

La mayoría de las piezas arqueológicas de acero examinadas están constituidas por aceros hipoeutectoides, con contenidos en carbono en masa que no superan el 0,2\%. Ocasionalmente se trató de aceros próximos a la composición eutectoide o, incluso, en algún caso aislado, se trató de aceros hipereutectoides. En la tabla I se indican las composiciones químicas de las muestras estudiadas, así como de las muestras de laboratorio.
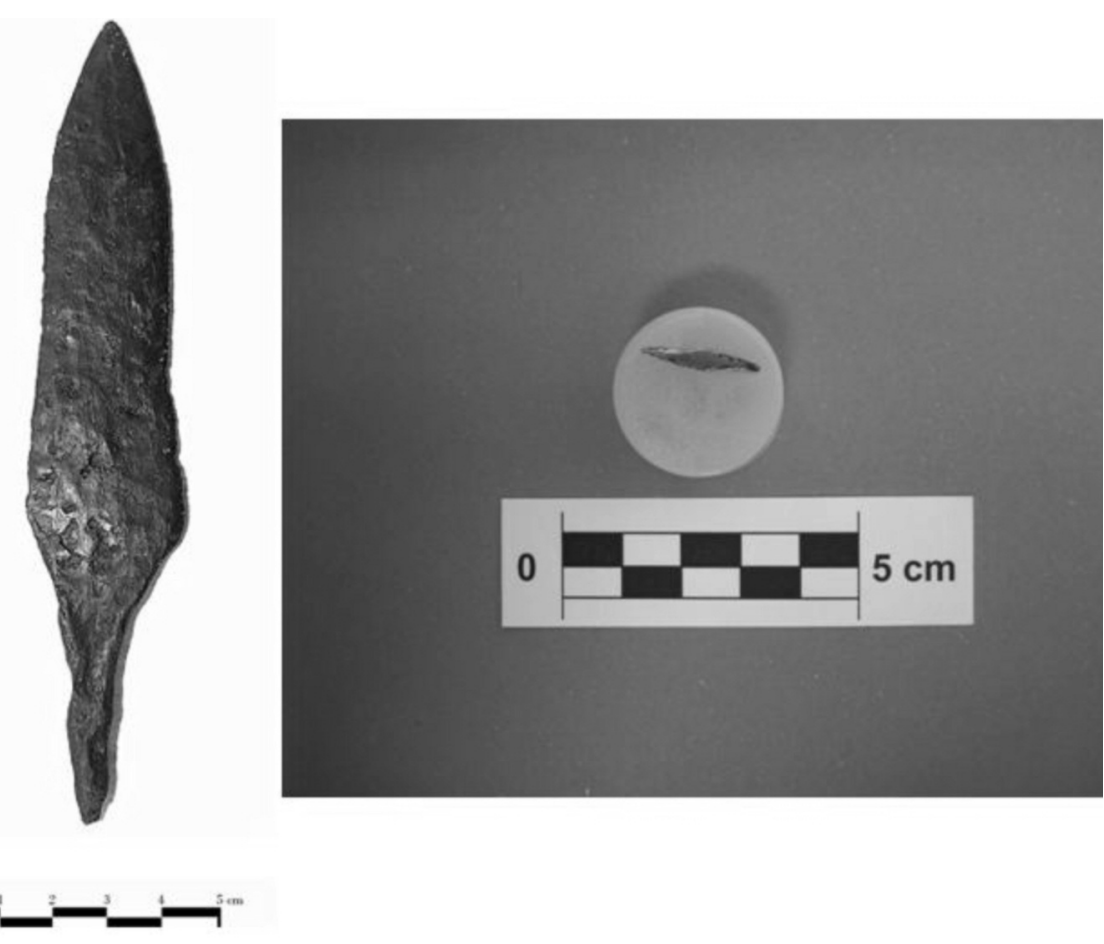

Figura 4. Imagen de la punta de lanza hallada en la Ciudad de Numancia (Soria) ${ }^{[8]}$.

Figure 4. Image spearhead found in the city of Numancia (Soria) ${ }^{[8]}$. 


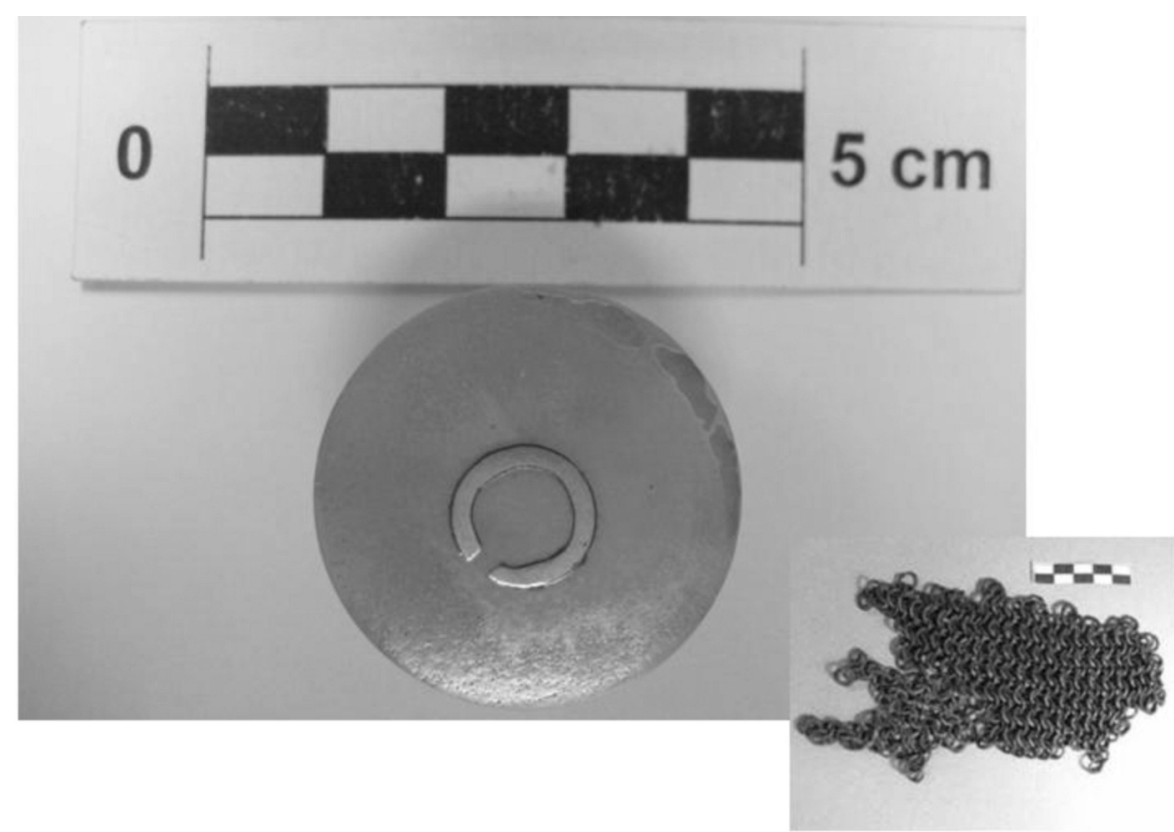

Figura 5. Imagen de la anilla de cota de malla hallada en el solar de casas al lado de la iglesia de San Vicente (Vitoria) ${ }^{[8]}$.

Figure 5. Image chainmail ring found on the site of houses next to the church of San Vicente (Vitoria) ${ }^{[8]}$.

Tabla I. Análisis químico de las muestras arqueológicas estudiadas y de las muestras realizadas en el laboratorio

Table I. Chemical analysis of archaeological simples studied and the samples taken in the laboratory

\begin{tabular}{lcccccc}
\hline Composición (\%) & C & Mn & Si & $\mathbf{P}$ & $\mathbf{S}$ & $\begin{array}{c}\text { Ni, Cr, } \\
\text { Mo }\end{array}$ \\
\hline Cota de malla & 0,13 & 0,50 & 0,30 & $<0,04$ & $<0,04$ & trazas \\
Punta de lanza & 0,17 & 0,45 & 0,30 & $<0,04$ & $<0,04$ & trazas \\
Clavo & 0,11 & 0,60 & 0,40 & $<0,04$ & $<0,04$ & trazas \\
Muestras laboratorio* & 0,15 & $0,40-0,70$ & $0,40-0,70$ & $<0,035$ & $<0,035$ & trazas \\
CK15 (DIN, Alemania) & & & & & & \\
C15K (UNE, España) & & & & & & \\
1015 (AlSI, EE.UU.) & & & & & &
\end{tabular}

* Análisis realizado por espectrofotometría de chispa.

En los aceros hipoeutectoides, las colonias perlíticas aparecen globulizadas, respetando la localización anterior al incendio (Figs. 6 y 7). Esto significa que el calentamiento superó los $720^{\circ} \mathrm{C}$ (temperatura eutectoide), pero quedando esto dentro de los límites del campo bifásico ferrita-austenita. Se trata de temperaturas de alrededor de los $760^{\circ} \mathrm{C}$ y tiempos no muy prolongados, de minutos a pocas decenas de minutos. En este caso, la colonia perlítica transforma a austenita, mientras que la ferrita resulta inalterada. Al cabo de unas decenas de minutos, la difusión puede afectar algo los límites de los cristales ferrítico-perlíticos, ahora ferrítico-austeníticos y, por tanto, modificar la geometría de la localización primitiva inicial. 


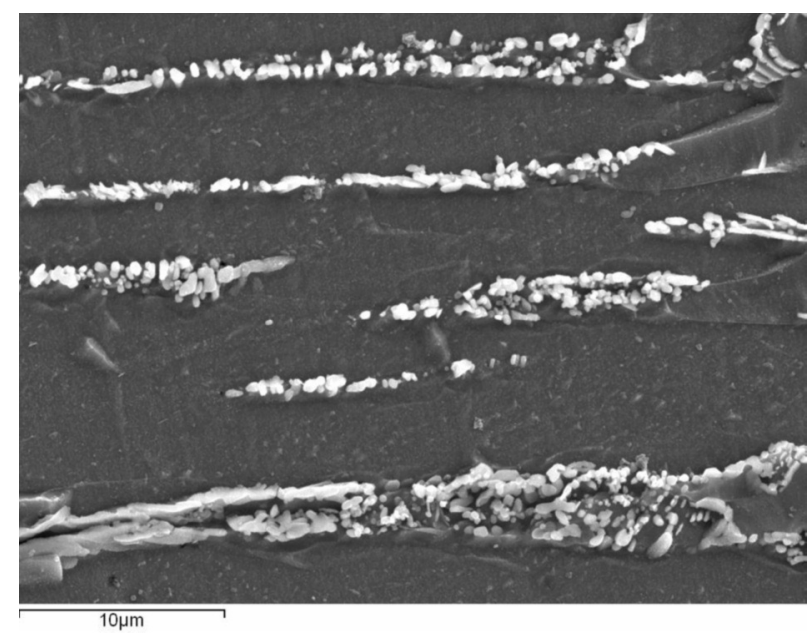

Figura 6. Micrografía del clavo de la Villa del Saucedo en la que se observan colonias de perlita globulizadas en los límites de grano, respetando la localización que tenía previa al incendio.

Figure 6. Nail micrography of the Villa del Saucedo in the observed globulized pearlite colonies in the grain boundaries, respecting the location that had pre-fire.

En la figura 8 se observa cómo se conserva esta localización inicial perlítica, en un experimento de laboratorio con un acero del 0,25\% C en masa, sometido a $760{ }^{\circ} \mathrm{C}$ durante $20 \mathrm{~min}$, y enfriado lentamente, a una velocidad inferior a $0,5^{\circ} \mathrm{C} / \mathrm{min}$. La colonia perlítica globulizada queda perfectamente dibujada en los límites de la primitiva colonia, anterior al tratamiento térmico. Este hecho se puede comprobar, asimismo, en las estructuras de incendio de la punta de lanza de Numancia (Fig. 9).

Si la temperatura de incendio es superior al campo de existencia bifásico ferrita-austenita y se sitúa en el monofásico de la austenita, en apenas $400 \mathrm{~s}$ de permanencia, se produce la homogeneización de todo el carbono en esta fase ${ }^{[5,6,9}$ y 10]. De esta forma ya no se conserva claramente la geometría primitiva de las colonias de perlita, apareciendo carburos globulizados muy dispersos, preferentemente en límites de grano, durante el enfriamiento (Fig. 10).

Si la pieza sometida a incendio tiene una composición en carbono muy próxima al eutectoide ( $\mathrm{H}<0,8 \% \mathrm{C}$ en masa), o bien, es hipereutectoide (>0,8\% C en masa), el testigo sólo identifica que superó en el incendio los $720^{\circ} \mathrm{C}$ de la temperatura eutectoide, ya que toda la matriz transforma a austenita. Durante el enfriamiento lento, la cementita globulizada aparecerá siempre repartida de forma homogénea por toda la matriz (Figs.11 y 12).

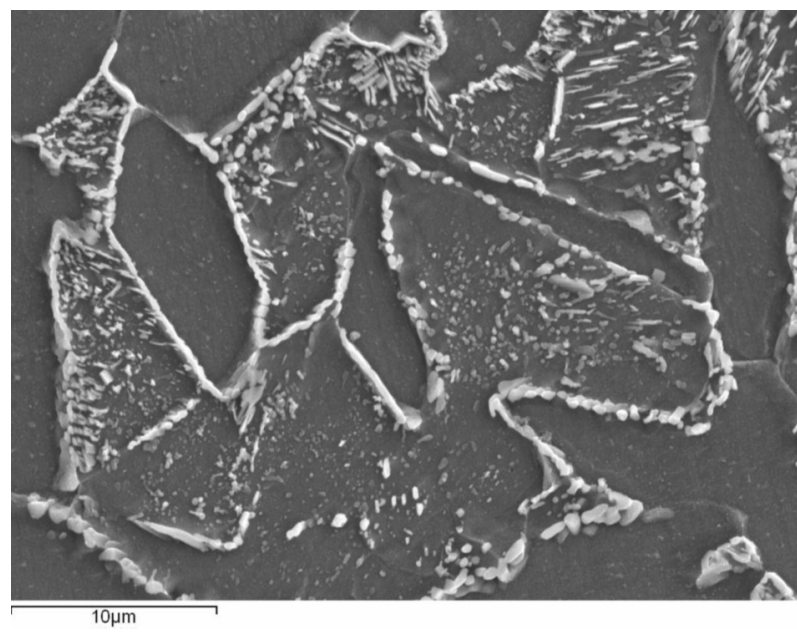

Figura 7. Micrografía de la punta de lanza de Numancia, en la que se observan colonias de perlita globulizada que dibujan los límites de grano donde se encontraban antes del incendio.

Figure 7. Micrography spearhead of Numancia, which are observed globulized pearlite colonies that grain boundaries drawn where they were before the fire.

En un experimento de laboratorio con un acero eutectoide, se calentó a $760^{\circ} \mathrm{C}$ durante 15 min y se dejó enfriar en el horno a una velocidad de enfria-

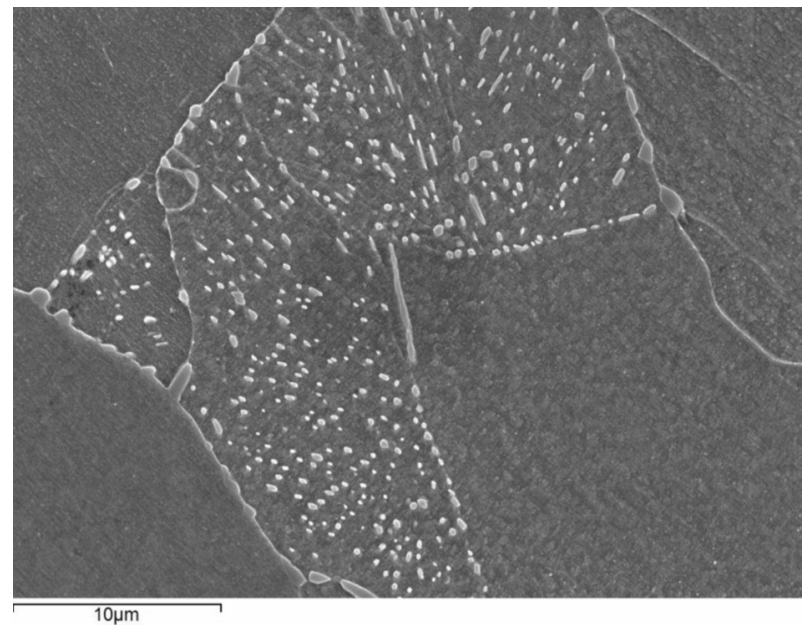

Figura 8. Micrografía de la estructura observada en el experimento llevado a cabo en el laboratorio con un acero del 0,25\% C en masa; en ella se dibujan claramente los limites de grano previos al ensayo con las colonias perlíticas globalizadas.

Figure 8. Micrography of the structure observed in the experiment carried out in the laboratory with a $0.25 \%$ C steel mass, drawn therein grain boundaries clearly pre pearlitic colony assay globulized. 


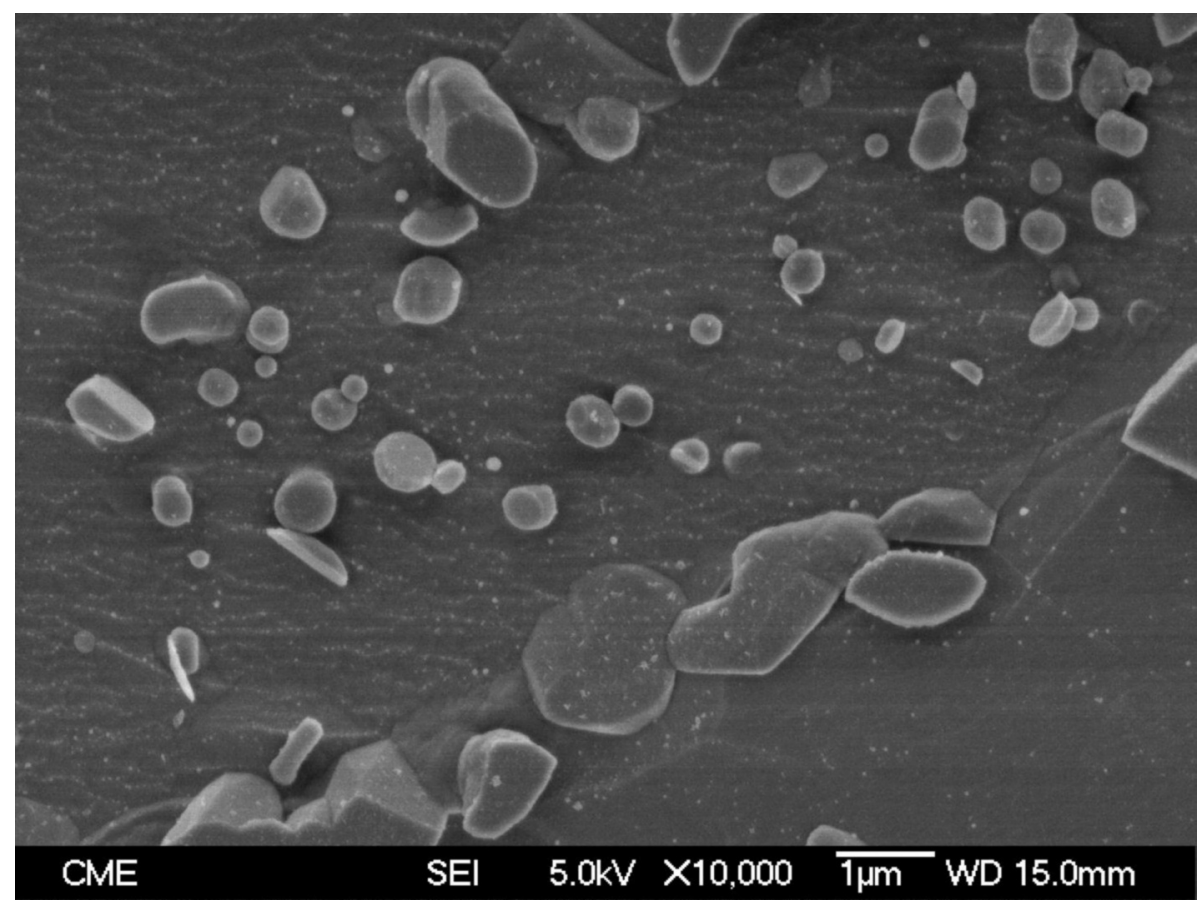

Figura 9. Micrografía de la punta de lanza hallada en la ciudad de Numancia en la que se observan colonias de perlita globulizada que dibujan los límites de grano donde se encontraban antes del incendio.

Figure 9. Micrography of the spearhead found in the city of Numancia observed in the pearlite colonies globulized that draw grain boundaries where they were before the fire.

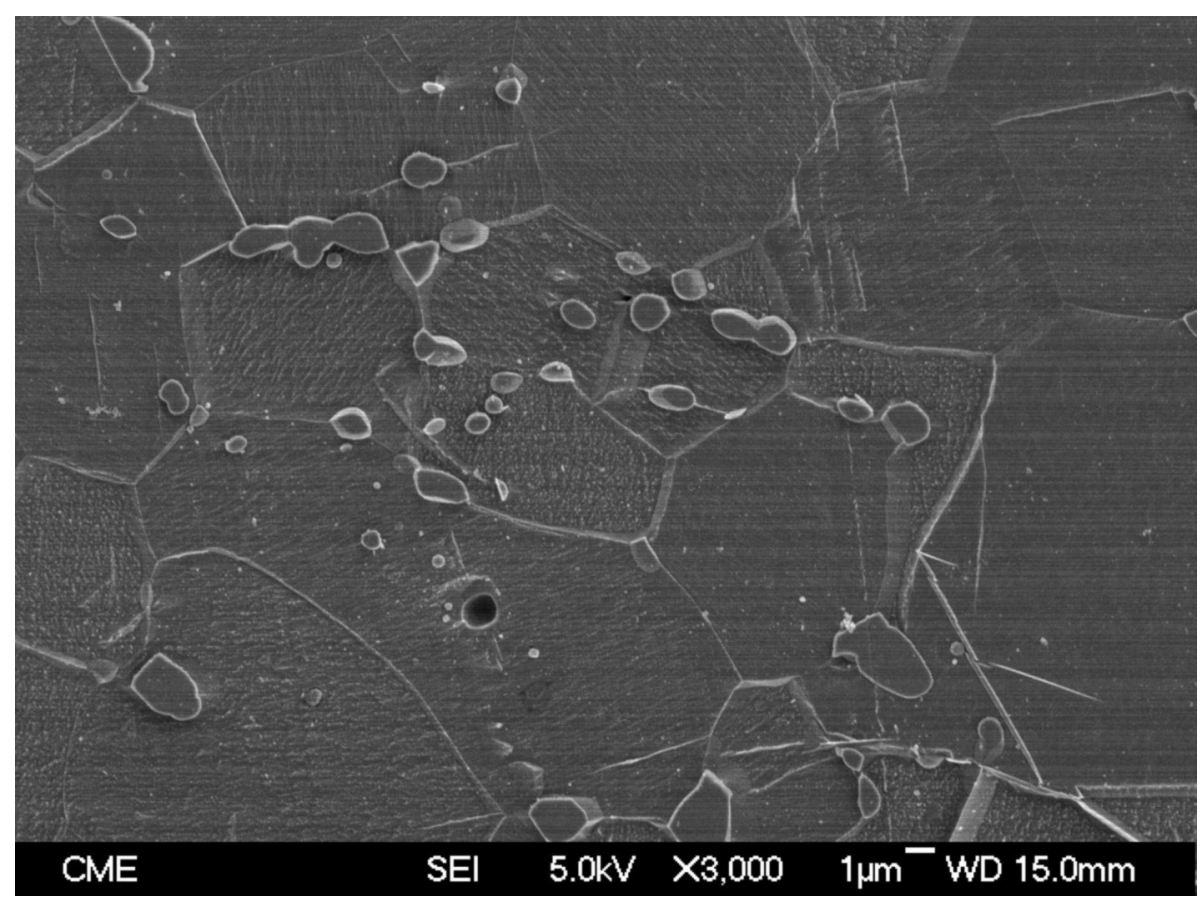

Figura 10. Micrografía de la cota de malla hallada en el solar de casas de Vitoria, en la que se observan colonias de perlita globulizada tanto en los límites de grano como en el interior de los mismos.

Figure 10. Micrograph of chainmail found in Vitoria solar houses, which are observed globulized pearlite colonies both grain boundaries and in the interior thereof. 


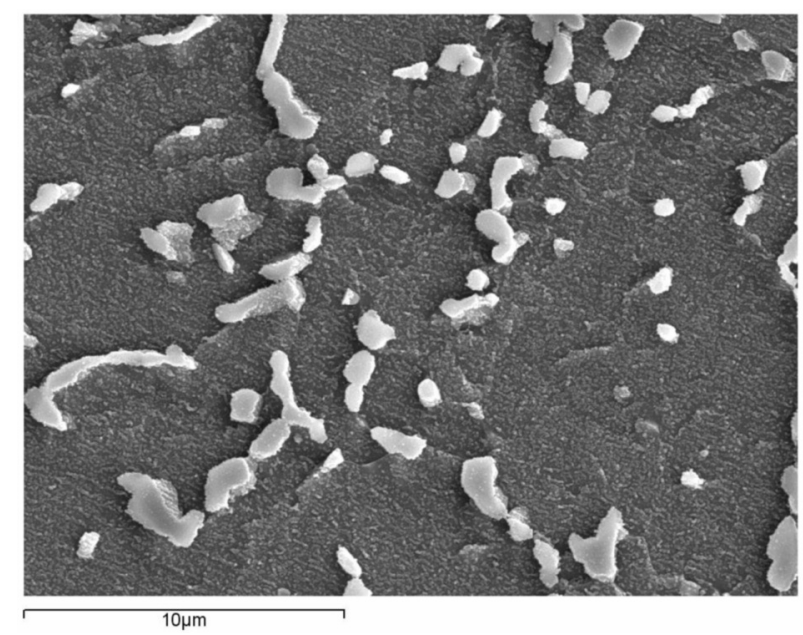

Figura 11. Micrografía del clavo de la Villa del Saucedo en la que se observa una matriz de austenita con cementita globulizada repartida homogéneamente.

Figure 11. Nail Micrography of the Villa del Saucedo at which austenite matrix with homogeneously distributed cementite globulized.

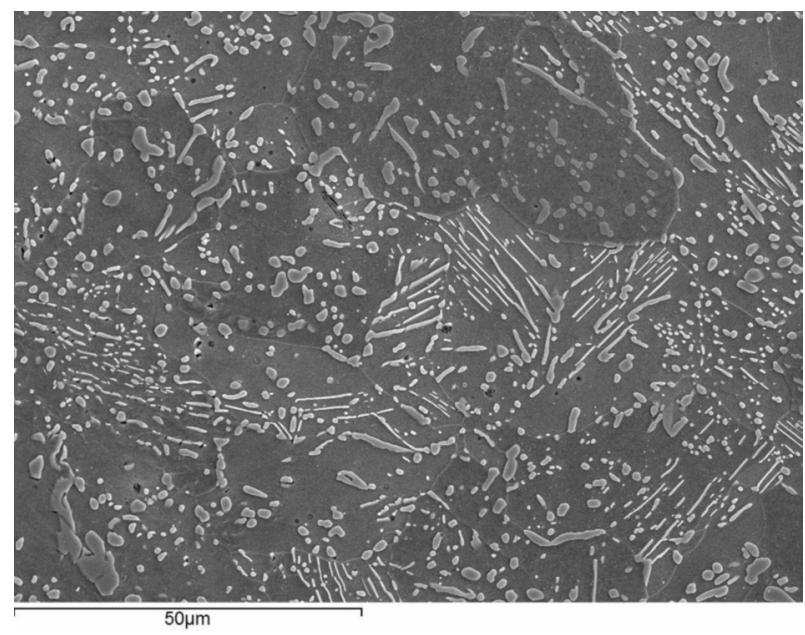

Figura 12. Micrografía de la estructura observada en el experimento llevado a cabo en el laboratorio con un acero eutectoide, en la que se observa el reparto homogéneo de los carburos de hierro globulizados por toda la matriz.

Figure 12. Micrography of the structure observed in the experiment carried out in the laboratory with a eutectoid steel, in the observed even distribution of globulized iron carbides throughout the matrix.

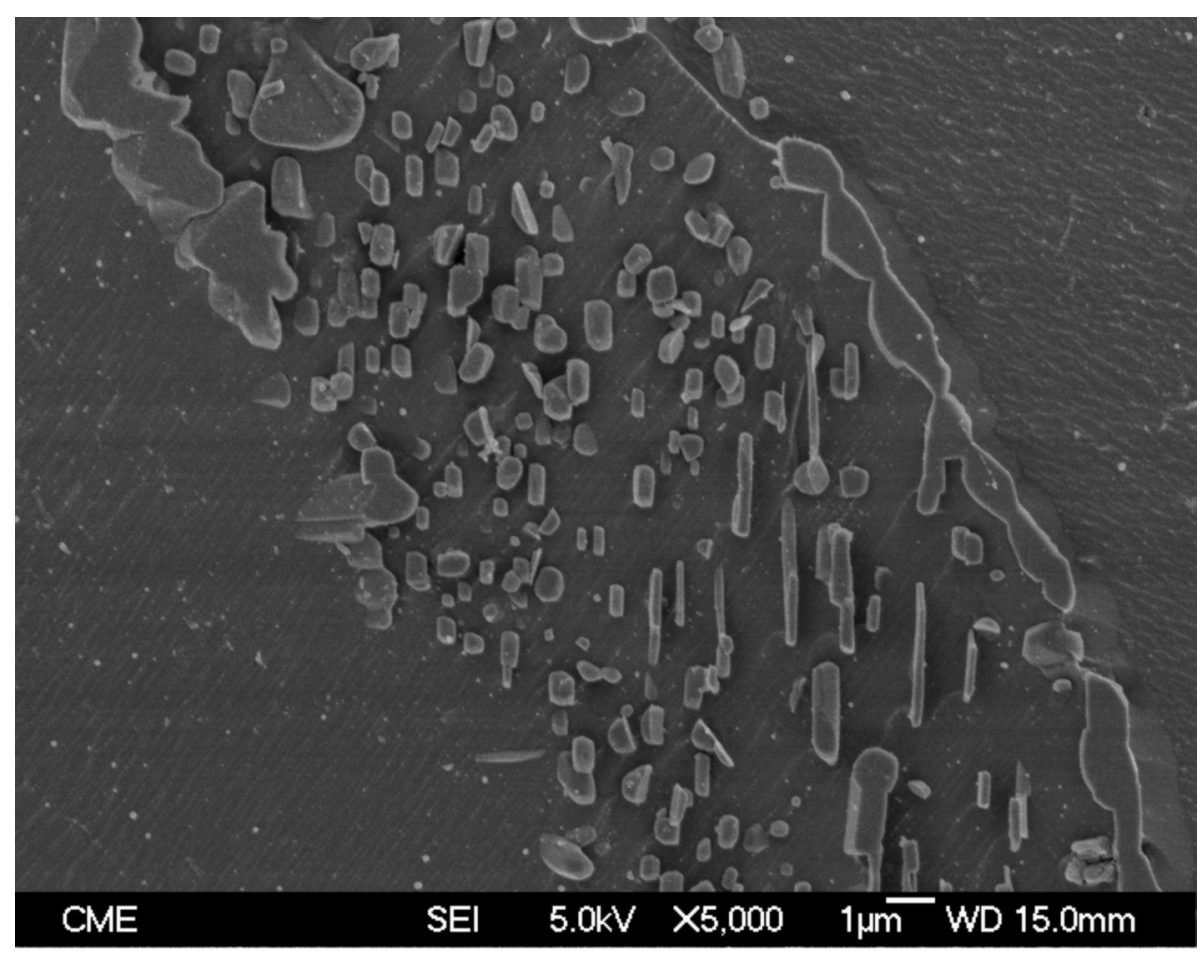

Figura 13. Micrografía de la punta de lanza hallada en la ciudad de Numancia en la que se observa la morfología poliédrica idiomórfica de los cristales.

Figure 13. Micrography of the spearhead found in the city of Numancia observed in the morphology of the crystals polyhedral idiomorphic. 
miento inferior a $0,5^{\circ} \mathrm{C} / \mathrm{min}$. En la figura 12 se puede observar cómo los carburos de hierro globulizados aparecen homogéneamente repartidos por toda la matriz.

La morfología globular de la cementita es sólo aparente y para bajas resoluciones, en microscopía óptica o electrónica de barrido. El carácter de compuesto intermetálico de la cementita provoca un crecimiento de tipo planar, con lo que la morfología final de estos cristales aparece con formas poliédricas idiomórficas (Fig. 12) ${ }^{[1]}$.

Para el caso de las muestras arqueológicas examinadas, se acentúa este proceso por difusión lenta, a temperatura ambiente, a lo largo de periodos de tiempo muy largos, como son siglos y milenios (Fig. 13) ${ }^{[11]}$.

\section{CONCLUSIONES}

- La aparición de estructuras perlíticas globulizadas, en piezas arqueológicas de acero, puede aportar información valiosa sobre lo ocurrido en el yacimiento arqueológico objeto de estudio. Se trata de un trabajo que nos informa sobre la existencia de un nivel de incendio. Para que se produzca la globulización de la cementita, es necesario un tratamiento térmico de calentamiento que, al menos, sitúe la pieza a temperaturas próximas al eutectoide $\left(\approx 720^{\circ} \mathrm{C}\right)$ o superiores.

- A la globulización de la cementita se puede llegar por dos procesos térmicos distintos:

a) Calentamiento muy prolongado (de 8 a $24 \mathrm{~h}$ ) a temperaturas inferiores pero muy próximas al eutectoide.

b) Calentamientos más o menos cortos (de minutos a horas) a temperaturas ligeramente por encima del eutectoide, seguidos de enfriamientos lentos a velocidades inferiores a $0,5^{\circ} \mathrm{C} / \mathrm{min}$.

- La mayoría de los incendios, que se produjeron en la antigüedad hasta la más reciente actualidad, encajan en el proceso descrito de tipo b. Este es el caso que, según nuestra opinión, se ha dado en los yacimientos arqueológicos estudiados, a tenor de las microestructuras observadas.

- La globulización de la cementita es un testigo clave en todos los casos en que se observe en piezas arqueológicas de acero, para discutir lo ocurrido en aquellos niveles en que se detecte su presencia.

\section{REFERENCIAS}

[1] G.A. Chadwick, Metallography of Phase Transformations, The Butterwhorth Group, New York, EE.UU., 1972, pp.188-194.

[2] D.A. Porter y K.E. Easterling, Phase Transformation in Metals and Alloys, Van Nostrand Reinhuld Company Ltd., London, England, 1981, pp. 279-287.

[3] R.E. Reed-Hill, Physical Metallurgy Principles, Litton Educational Publishing International, New York, EE.UU., 1973, pp. 661-701.

[4] W. Rostoker y J.R. Dvorak, Interpretation of Metallographic Structures, Academic Press, New York, EE.UU., 1977, pp.75-120.

[5] F.A. Calvo, A.J. Criado, J.M ${ }^{a}$. Gómez de Salazar y F. Molleda, Rev. Metal. 21 (1985) 312-316.

[6] F.A. Calvo, A.J. Criado, J.Mª . Gómez de Salazar y F. Molleda, Rev. Metal. 21 (1985) 342-345.

[7] J.E Taylor, Journal The Annals of Mathematics 103 (1976) 489-539.

[8] J.A. Criado Martín, Tesis Doctoral, Facultad de Geografía e Historia, Universidad Nacional de Educación a Distancia, Madrid, 2012.

[9] F.A. Calvo, A.J. Criado, J.Mํa . Gómez de Salazar y F. Molleda, United States Army, Research and Standardization Group, London.

[10] F.A. Calvo, A.J. Criado, J.Mª . Gómez de Salazar y F. Molleda, Rev. de Soldadura, Vol XI (1982) 105-111.

[11] E. Bravo, J. Chamón, J. Guzmán, R. Arévalo, A. Javier Criado, C. Dietz, J.A. Martínez y A.J. Criado Portal, Journal of Nuclear Materials 349 (2006) 1-5. 